\section{Evidence summary: does dentists' fear have an adverse effect on clinical decision-making?}

\author{
Developed from the original question submitted \\ by D. Andrew Lane, May 2010 \\ Reviewer: Chris Fox \\ Information Scientist: Helen Nield
}

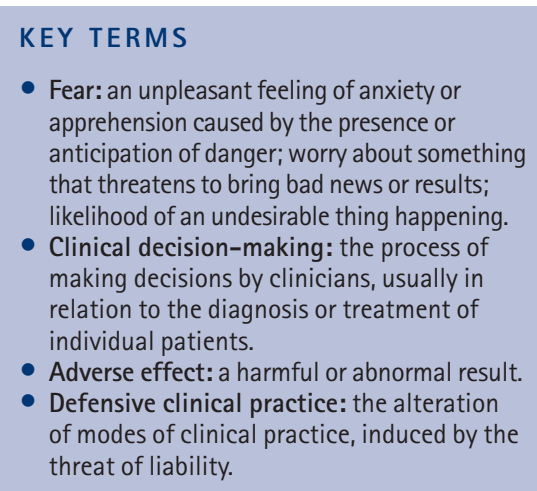

Since August 2009, members of the Primary Care Dentistry Research Forum (www.dentistryresearch.org) have taken part in an online vote to identify questions in day-to-day practise that they felt most needed to be answered with conclusive research. The question which receives the most votes each month forms the subject of a critical appraisal of the relevant literature. Each month a new round of voting takes place to decide which further questions will be reviewed. Dental practitioners and dental care professionals are encouraged to take part in the voting and submit their own questions to be included in the vote by joining the website.

The paper below details a summary of the findings of the eighth critical appraisal. In conclusion, the critical appraisal found no studies that identified the nature and extent of dentists' fears. Nor did the appraisal find any studies that assessed how dentists' own fears impact upon clinical decision-making. It would appear that this subject is novel territory for primary research.

\section{BACKGROUND}

A literature exists about patients' fears of dental treatment, ${ }^{1}$ and also of dentists' options for clinical management of their patients' fears. ${ }^{2,3}$

But what insight does the literature offer about dentists' own fears? What impact may this have upon professional practice?

'How often does fear affect your clinical decision-making?' Sixty-one percent of participants $(n=62)$ in a recent member survey ${ }^{4}$ on an online UK private access mailing list for dentists for dental opinion and information ${ }^{5}$ answered 'daily' to this question. Only $14 \%$ reported that fear never affected their clinical decision-making.

\footnotetext{
${ }^{1}$ PhD Student, Peninsula Dental School

Correspondence to: Arianne Matlin, British Dental Association, 64 Wimpole Street, London, W1G 8YS Email: info@dentistryresearch.org:

Tel: +44 (0)2075634583

Sponsored by

the Shirley Glasstone Hughes Trust
}

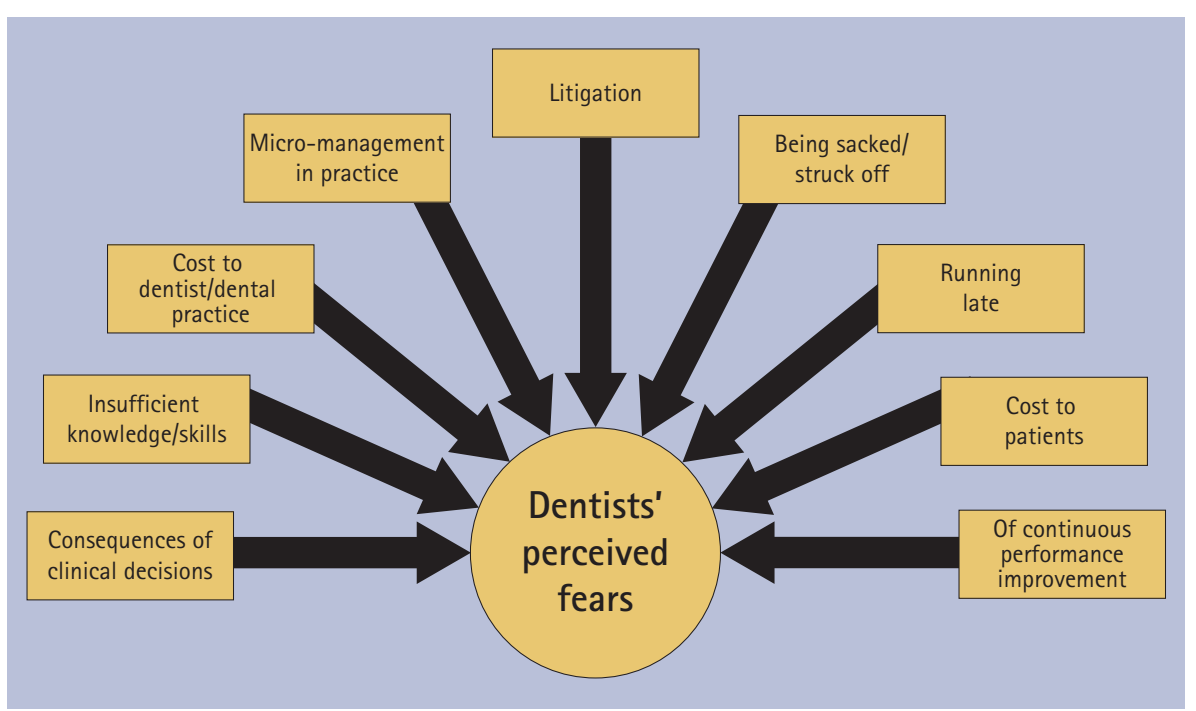

Fig. 1 Fears reported by dentists (GDPUK online survey, 2010)

Dentists' informally-reported fears are diverse (Fig. 1). These fears may be inhibitory to clinical activity, such as a fear of litigation, potentially leading to defensive practice. Conversely, continuous clinical performance improvement may in part be stimulated by dentists' fears. A further dimension that has been reported is that 'we have nothing to fear but fear itself'. ${ }^{6-9}$

\section{AIM}

This review aimed to use research evidence to construct a comprehensive list of the fears of primary care dentists. In addition, to try to identify research which shows how any dentists' fears impact upon their clinical decision-making. 


\section{REVIEW METHOD}

An initial search was made of Ovid MEDLINE $^{\circledR}$ (1950 to week 4, April 2010) using the search terms fear, decisionmaking, clinical competence, patient care planning, choice, and behaviour. Sixty-nine titles were identified and 14 papers retrieved as full text and examined; 69 titles were rejected.

Further searches included CEBD, Cochrane Oral Health Group, CRD, ADA, TRIP database, DARE, NHS Evidence QIPP, social sciences databases (Science Direct, ASSIA (CSA), Web of Science, EBSC0, SwetsWise), and individual journal searches including EvidenceBased Dentistry, Journal of EvidenceBased Dental Practice, and Journal of the American Dental Association. Two hundred and ninety-nine titles were identified, and all 299 titles rejected.
Further contact was made with Dr Andrew Lane, the review question originator, to confirm the subject of the question.

\section{FINDINGS}

Three hundred and sixty-eight titles and abstracts arising from the bibliographic and web-based searches were screened. Fourteen potentially relevant papers were retrieved as full text and reviewed. Ultimately none of these 14 papers provided relevant findings.

We could find no studies that identified the nature and extent of dentists' fears. Nor could we find any studies that assessed how dentists' own fears impact upon clinical decision-making.

It appears that exploration and understanding of fear amongst dentists, and also the mechanisms and degree to which this may impact upon clinical decision-making, is novel territory for primary research.

1. Armfield J M. Towards a better understanding of dental anxiety and fear: cognitions vs. experiences. Eur J Oral Sci 2010; 118: 259-264.

2. Mellor A. Management of the anxious patient: what treatments are available? Dent Update 2007; 34: 108-110, 113-114.

3. Kvale G, Berggren U, Milgrom P. Dental fear in adults: a meta-analysis of behavioural interventions. Community Dent Oral Epidemiol 2004; 32: $250-264$

4. The role of fear in clinical decision-making. GDPUK online survey. http://www.gdpuk.com/forum/ viewtopic.php?t=4881 (private access website, accessed 5 May 2010)

5. GDPUK website. http://www.gdpuk.com/ (accessed 23 May 2010)

6. Winland R D. Conquering fear. Editorial. AGD Impact 2006; January.

7. Duquette $A$ M. Nothing to fear but fear itself. $R D H$ 1993; 13(6): 28-30, 32, 50

8. Flower J. Why it matters. Physician Exec 1998; 24(2): 43-45.

9. Clever L H. A checklist for making good choices in trying - or tranquil - times. West J Med 2001; 174: 41-43. 